\title{
Design and art promoting socially responsible recycling: the analysis of a collaborative action to support waste pickers in New York City
}

\author{
Silvia Resende Xavier ${ }^{1, a}$ and Luciana dos Santos Duarte ${ }^{2}$ \\ ${ }^{1}$ The New School, Parsons School of Design, $665^{\text {th }}$ Ave, New York/NY, USA \\ ${ }^{2}$ Federal University of Minas Gerais, Engineering School, Av. Pres. Antônio Carlos, 6627, Belo Horizonte/MG, Brazil
}

\begin{abstract}
The possibility of recovering discarded materials and selling them for revenue leads many individuals worldwide to engage in waste collection. This situation is observed in New York City, where waste pickers collect discarded beverage containers in the streets. Although contributing to recycling in the city, these workers face political and social obstacles. This study aims to investigate actions that support waste pickers worldwide, as well as their potential for exchange. Some specific goals are to examine the development of a Brazilian project in the context of recycling in the USA, and to evaluate the social and environmental outcomes of a design and art collaborative action. The methodology for this research-andpractice based study comprises a theoretical review, a field research to gather qualitative data, and a case study of an action promoted within the scope of this work. When analysing the results of this study, the contribution of design and art action is evidenced, and three important findings are highlighted: the relevance of a sense of identity for waste pickers; the importance of waste pickers being visible within the urban environment; and the potential for changes in the interactions between waste pickers and other citizens. Finally, this study accomplishes the goals of employing design and art to promote a socioenvironmental action based on a collaborative model, and of evaluating the outcomes of this experience exchange between a Brazilian project and a NYC based organization.
\end{abstract}

Keywords. Waste management, Recycling, Waste pickers, Collaborative action, Social design.

\section{Introduction}

Waste management is crucial for the functioning of cities. Over the years, different technologies were developed to deal with the materials we discard and different actors have been involved in the management of residues. Further, various drivers have influenced the development of waste systems at different periods. Some examples are the concern for public health raised during the sanitary movement in the late 1800s and the pressure for the preservation of natural resources influenced by the environmental movement in the 1970s (WILSON, 2007).

In current waste management systems, we observe a combined influence of many factors. For instance, in most major urban centers, it is taken for granted that public space cleaning is a public health concern and that local governments are responsible for managing the city waste systems. Environmental preservation is also an important driver influencing current practices, such as making recycling mandatory. Furthermore, the resource value found in waste, which has been a main driver for waste management since the Middle Age, is still a driver for waste collection today.

a Corresponding author: silvia@newschool.edu
The possibility of recovering discarded materials and selling them for a revenue leads some individuals, often marginalised and excluded from the formal employment market, to engage in waste collection. As recycling has a major role in reversing the economic value attributed to discarded matter, recyclable materials are the residues that have the highest economic value nowadays (TEODOSIO and DIAS, 2014).

In urban centers, the consolidation of the recycling market has an important social function as it enables a part of the urban population to participate in an economic activity. When discussing the activities developed by the population living in economically impoverished situation in São Paulo, Harland and Santos (2014) point out that:

A significant number of this population live on the streets, where they develop their survival repertoire that involves material collection and recycling, what is known as 'catação'. It is a selfcreated economy that reuses the trash and leftovers of the city. Recyclable material collecting sometimes reaches or surpasses the minimum wage.

The situation described by Harland and Santos can be observed in many other urban centers around the world. 
Gowan (1997) points out that informal waste picking is a common practice also in many cities in the United States, stating that:

Over the last ten years, the US recycling industry has mushroomed on both the formal and informal levels, taking the form of a double tiered system which relies heavily on informal labor for sorting and collection, while reprocessing is dominated by large capital enterprises.

Wilson (2007) affirms that the recovery and trade of discarded materials is a key activity that connects the urban poor in many parts of the world to waste management, creating the 'informal sector'. Throughout time, formal and informal waste systems codeveloped and different interactions between these two systems were consolidated in different cities.

This study focuses on the situation of individuals who engage in informal waste collection both in Brazilian cities and in New York City, USA. In most Brazilian cities, the workers who autonomously collect recyclables in the streets are known as 'catadores' and their activity has been legally recognised by the government. On the other hand, in New York City (NYC), the workers collecting recyclable materials are called 'canners' and their activity is not legally recognised by city authorities, leading to marginalisation and even criminalisation.

Although living in different realities and under different legal frameworks, catadores and canners face similar challenges. In both cases, these workers are the weak link in the recycling chain and are often undervalued. In addition, there are different layers of invisibility and prejudice involving their activity, such as informality, the social and economic situation of the individuals and the stigma for dealing with discarded materials. However, there are some initiatives to promote the recognition and inclusion of waste pickers in both realities.

In this context, we highlight two initiatives: (i) Pimp My Carroça, which is a social, artistic and cultural movement initiated in Brazil in 2012; (ii) Sure We Can, which is a non-for-profit recycling center operating in NYC since 2007. These two initiatives are connected in this study, which aims to investigate actions that support waste pickers worldwide, as well as their potential for exchange. Some specific goals of this study are to identify the main difficulties faced by canners in NYC; to examine the development of a Brazilian project in the context of recycling in the USA; and to analyse the results of a collaborative design and art action in promoting socio-environmental development.

\section{Methodology}

Within the scope of this research-and-practice-based study, qualitative data was gathered during field research and interviews. Moreover, an on-the-ground action was carried out to be the object of a case study. The methodology for this work is organized in four phases. Firstly, the theoretical basis is built through literature review and aims to identify the economic, political, social and cultural aspects that influence the discussion about the inclusion of waste pickers in NYC. Secondly, for the exploratory phase of this study, semi structured interviews were conducted with canners in NYC, focused on gathering information about their activity, their interaction with the urban environment and their relationship with other citizens. The third part of this methodology is the experimental phase. During this phase, the concepts highlighted in the literature review are juxtaposed with the data obtained through the exploratory phase. Finally, the fourth stage comprises the implementation and evaluation of an intervention and an analysis of the results of this research and practice study.

\section{Development}

This work starts with a review of the challenges faced by waste pickers in NYC, taking into account the legal frameworks, the information available thought media channels and through official documents, and the interviews carried out during the field research. In addition, two social and collaborative models are presented, evidencing their actions to support waste pickers and their potential for exchange. Furthermore, a collaborative action employing art and design is implemented in NYC, involving waste pickers, local residents and non-for-profit organizations. Lastly, the information collected through field research and action is aligned to the theoretical concepts exposed in the literature review, as a way to describe and analyse the results of this study.

\subsection{The recycling systems operating in NYC}

New York City inhabitants and businesses discard a total of 14 million tons of mixed materials per year (NYC MAYOR'S OFFICE, 2016) and parallel systems were developed to deal with the complex nature of these discarded materials. While the city relies on The City of New York Department of Sanitation (DSNY) and on private companies to collect residential and commercial waste, there are alternative waste systems. Some examples are voluntary drop off sites, small scale pick up operations, and autonomous waste pickers.

Waste management in NYC can be considered successful for being able to remove from the city large amounts of discarded matter every day. However, in terms of material recovery, waste management is inefficient and unsustainable. Although $60 \%$ of the materials discarded by NYC residents have the potential to be diverted from disposal through recycling and composting (NYC DEPARTMENT OF SANITATION, 2013 ), only $17 \%$ of these materials are retrieved by the 
city's collection programs (GROW NYC, 2016). This is approximately one third of what could be diverted from landfills. It is also a low diversion rate if compared to other cities in the United States, as the national average diversion rate is $34.3 \%$ (US EPA, 2016). Since its launch in 1989, the city's recycling program has undergone various changes. Although never particularly successful in achieving high diversion rates, it has always been a central piece in the city's efforts to structure a sustainable waste management system.

Besides the municipal recycling initiative, there is another recycling program running in NYC. The Returnable Container Act (also known as the "Bottle Bill") is an Extended Producer Responsibility (EPR) law promoted by New York State in the early 1980s to incentivize recycling (NYS DEC, 2016). This law mandates a five-cent deposit upon purchase of some bottled beverage, meant to motivate consumers to return the empty container for recycling. The Bottle Bill also creates the physical structure to retrieve the post consumption containers - the redemption centers, where the consumers can exchange each empty bottle by five cents - and obliges the beverage producers to handle the returned containers for recycling (NYS DEC, 2016).

In practice, consumers nowadays rarely return their empty containers to retrieve the five-cent deposit and these containers are placed at the curbside with other discarded materials. The economic value embedded in these bottles allows for people to earn a living by collecting and returning them to the redemption centers. These individuals - also known as canners - usually work autonomously and, by using the structure created by the Bottle Bill, they are involved in a formal-informal hybrid system of selective collection in NYC.

Even though all these systems - the municipal program, the Bottle Bill, and the work of canners contribute to divert materials from landfills and to direct them to recycling, there is a tension generated by their overlap. According to DSNY (2012), parallel waste collection practices can undermine the municipal recycling program. City authorities argue that, because of the work of autonomous waste pickers, the amount of valuable recyclable materials retrieved by the city decreases, which reduces the revenues that the city would receive by selling these materials to the recycling industry. The cost of the municipal recycling program is partially paid by the money earned through the trade of recyclable materials, thus the reduction of this revenue means more expanses to the city (DSNY, 2012).

The city authorities' discourse focuses mostly in economic arguments, neglecting social aspects involved in the recycling system. Taken aside the dispute over the economic value of discarded materials, waste pickers' activity actually aligns with the city's goals for waste management and to the city's commitment to equity and social justice. First, because it contributes to retrieve materials for recycling, diverting them from landfills. Second, because it allows underprivileged individuals to earn an income by engaging in a productive and environmentally sound activity.

\subsection{Who are the canners}

The information for this research comes from the interviews carried out with five canners, two of which were followed during a day of 'canning'. Eugene, Pierre and George are Afro-Americans and were interviewed in Brooklyn, NYC. Jorge and Jose are Latin-Americans and were interviewed in the streets of Manhattan, NYC.

First, it is important to highlight the fact that NYC canners form a group of diverse individuals. The diversity of languages, cultural backgrounds and motivations make the category 'canners' a rather disconnected group, which may be one of the reasons why there is no history of self-organization efforts.

Taken aside the differences, one common point mentioned by all interviewees is the reason for engaging in waste picking: the need to earn money, often after unemployment. While Jorge mentioned that he started canning after he lost his job in a furniture industry, George said he engaged in this activity because he was "broke" and he realized he could supplement his income with canning. In this sense, Eugene mentioned that he started canning because he was unemployed. He said he could make around US\$100 per day, which means collecting 2000 discarded bottles.

When asked about the positive aspects of this activity, the most common answers were autonomy for time management, immediate pay, and the possibility of having a productive activity without a formal employment. For example, Pierre was especially emphatic in expressing the feeling of joy and freedom that he often has when walking the streets and collecting the cans and bottles.

In contrast to the narrative promoted by DSNY, the canners who were interviewed consider that their activity is a legitimate work that provides a service to the city. Eugene affirmed that 'canning' is an actual job and he expressed his satisfaction for contributing to recycling. Similarly, most canners considered that waste picking is a worthy activity that adds to recycling in the city.

\subsection{The challenges faced by the canners}

The tension between waste pickers and DSNY, exposed in section 3.1, is a big challenge that NYC canners face in the political sphere. However, this is not their only difficulty, as canners also find obstacles in the social sphere.

One challenge for the social recognition of canners relates to the fact that they deal directly with the materials we discard. Generally, in the western culture, waste is associated to ideas of loss, impurity, repulsiveness, danger and contamination; it is considered to be undesirable and should be kept away ( $\mathrm{LYNCH}$, 
1990). These negative feelings affect people's perception of the individuals who deal with waste. As pointed out by Wilson (2007), "one constraint here can be cultural: if waste is viewed in some way as 'dirty,' then waste management will be viewed as "not an honorable profession." In fact, a canner who was interviewed for this study mentioned that people often turn away or neglect his presence when passing by him.

Another obstacle identified for the social integration of canners in NYC refers to the situation of class segregation and prejudice engrained in society. Canners in NYC are usually low-income individuals, immigrants or part of minority groups, which contributes to further marginalization. As Pereira and Teixeira (2014) point out:

Waste pickers are inserted into social relations in which social inequality is daily naturalized (...) so that they constitute a class excluded from all material and symbolic opportunities of social recognition.

Moreover, the invisibility of waste systems in the urban environment contributes to create a layer of invisibility for the workers dealing with residues. Nagle (2013) quotes the work of sociologist Wayne Brekhus to affirm that the workers engaged in waste collection are an example of an "unmarked" element of daily life. Nagle (2013) states that waste related workers are "engaged in unmarked labor, and are themselves unmarked laborers." In fact, the canners who were interviewed mentioned that people rarely notice their presence, even though they often pass by the same route and recurrently see the same residents.

\subsection{Sure We Can, a counter narrative in NYC}

In spite of the difficulties faced by canners in NYC, there are initiatives to support these individuals and promote their inclusion. Sure We Can (SWC), a non-forprofit redemption center, is highlighted in this study. Since its foundation in 2007 , it has grown to be not only a place for NYC canners to exchange their bottles for money, but also a safe space where they can get support and participate in social and cultural exchanges. As stated in their web page: "Sure We Can has evolved into a community building and sustainable living hub committed to fostering a resilient urban culture" (SWC 2016).

SWC is part of a counter narrative, working in a way that conciliates canners and the city efforts for recycling. For instance, SWC keeps records of all materials received daily and of the canners who bring the materials, thus creating data for this system. Furthermore, SWC accounts for the social benefits of the recycling system, and promotes not only material and economic exchange, but also social exchanges and the value of individuals.

\subsection{Pimp My Carroça, a Brazilian project to support waste pickers worldwide}

Besides highlighting local initiatives to improve canners' situation in NYC, this study identified projects that aim to support waste pickers in other contexts. In this broader perspective, the Pimp My Carroça (PMC) project is highlighted as an initiative to promote civic and political awareness about the situation of waste pickers. The project was initiated in São Paulo, Brazil, by the artist Thiago Mundano in 2012. Amongst other actions, one of the main activities promoted by PMC is to reform and to artistically paint waste pickers' carts, and to donate safety equipment to the workers.

The project's methodology allows for the action to be initiated by any individual interested in supporting waste pickers worldwide. Further, the intervention through design and art contributes to approximate waste pickers and other citizens, and to instigate changes in the way people perceive waste pickers in the streets. This project is highlighted because it employs a collaborative model in order to trigger change in social relations, resulting in socio-environmental benefits.

\subsection{Implementing a collaboration between Sure We Can and Pimp My Carroça in NYC}

Considering its goal and its methodology, the PMC project was identified as suitable for implementation in NYC, having the potential to support canners in the social sphere. Hence, a PMC action was planned and carried out in partnership with SWC, to improve canners working condition and foster civil society support in legitimizing their work. Through the analysis of the action results, it is possible to evaluate the outcomes of this collaborative model and its contribution to social and environmental improvements in an urban context.

In practice, the collaborative action happened in the course of nine weeks, and culminated with the realization of the "Pimpex NY" on 9th April 2016. Members of Pimp My Carroça in São Paulo and members of Sure We Can in New York City were involved in this process. Throughout February and March, the team planned the costs and activities, recruited the canners and artists, redesigned the carts for the reform, and promoted a successful crowdfunding campaign to raise the money necessary for this realization (PIMPEX NY, 2016).

During the action day, nearly 30 people were present at Sure We Can to help as volunteers, four carts were painted and reformed, and the canners were provided with equipment. Six artists were involved in reforming and painting the carts, one of them is show in Figure 1. 


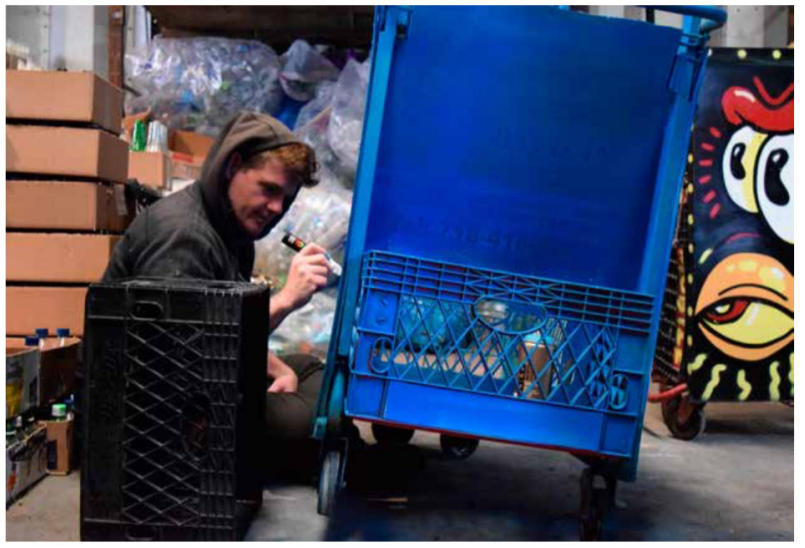

Figure 1. Artist Skewville painting one of the carts.

The canners - Eugene, Pierre and George participated in part of the reform and received a package with safety equipment. Some items included in the package are rain-cloths, gloves, rope, glasses, flashlight, bags, t-shirt with reflective band. Each canner received a kit with these items.

Notwithstanding, the involvement of the artists and canners allowed for a fruitful interaction contributing to the redesign of the cart according to the user needs. Figure 2 depicts one of the canners using his cart after the action.

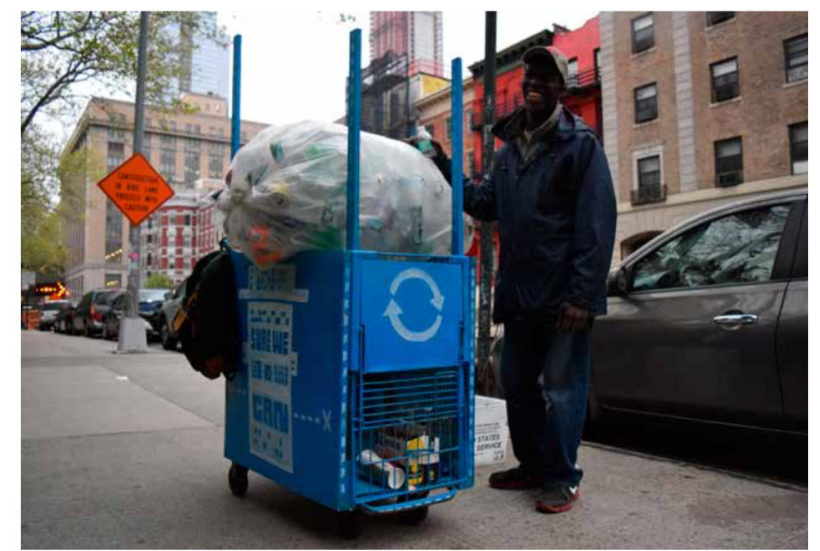

Figure 2. Eugene using his new cart in the streets.

\section{Result analysis}

The implementation of this collaborative action, the donation of equipment and the reform of the cart are concrete actions that led to tangible and intangible improvements in the canners' daily activity. Three important outcomes are highlighted and analysed: (i) the sense of identity and pride expressed by the canners; (ii) the fact that they become more visible in the city environment; (iii) the changes in the relationship with other citizens.

Firstly, the redesign of the carts made them more functional and efficient, providing more space to carry materials, sticks to hang items, and a compartment for personal objects. Besides these functional changes, the makeover of this object through design and art is a powerful means to foster identity and empower the canners. This feeling was expressed by Eugene, who said he felt happy to have a cart made especially for his use, expressing sentiments of pride and worthiness. Furthermore, the redesigned carts are mobile devices that now convey the canners' messages throughout the city. Pierre's cart, for example, was painted with musical notes allusive to his background as a musician, and with Sure We Can logo because he wanted to bring attention to the organization.

Concerning the issue of visibility, canners constantly share sidewalks and streets with other individuals and other vehicles. Although, they should be seen and respected, they often go unnoticed. The cart is the tool canners have to negotiate his or her participation in the public space. In this context, the carts painted during the collaborative action stand out because of their design and colors, making the canners more visible and marking their presence in the city. For instance, Eugene reported that, after he started using the new cart in the streets, people would look more at him, acknowledging his presence.

In an analogous situation, Smith (1992) analyses the results of the Homeless Vehicle project, which proposes the redesign of shopping carts to adapt them to the needs of homeless persons. Smith (1992) states that the Homeless Vehicle is "a mean to carve a more sympathetic geographical politics in a city of exclusionary spaces." In a similar way, the redesigned and artistically painted carts enable the canners to use their own working tool to mark their presence. In the words of Smith (1992), it enables canners to "erase their own erasure".

Lastly, regarding the relationship between canners and other citizens, it has been identified during the field research that interactions rarely occur, mainly because of social and economic differences. The redesigned cart, in this case, works as a catalyzer for interactions between canners and other citizens. As reported by Pierre, some people who were curious about the cart stopped him in the street to take pictures and to have a conversation. The new cart, as a mobile art piece, not only brings more visibility but also creates the space for approximation and conversations. This approximation between canners and other citizens is important because it dissolves social barriers and encourages dialog, triggering changes in public perception about waste picking.

\section{Conclusions}

The carts and the collaborative action that generated them are mechanisms to trigger change in public perception about waste pickers in NYC, contributing to the reconceptualization of the activity. Both the carts and the collaborative action are means to amplify the message and the social network to support canners. As 
mobile artefacts, the carts carry a message throughout the city, reaching an unpredictable audience. As a joyful and unexpected situation, the collaborative action gained media attention, spreading a positive counter story to the city's discourse. Further, the collaboration between Sure We Can and Pimp My Carroça was succesful and is expected to consolidate over time, contributing to the exchange of experiences between these two organizations and between waste pickers living in different realities.

Finally, this research and practice study accomplishes the goals of promoting a social and environmental action based on a collaborative model, and of evaluating the outcomes of this experience exchange between a Brazilian project and a NYC based organization. Besides the participation of canners, this study involved diverse interested parties such as artists, designers, university, and the members of civil society. Those are agents in promoting the legitimization the canners' activity and in contributing to a socially responsible and environmentally sustainable waste management system in NYC in the long term.

\section{Acknowledgments}

The authors would like to thank: Sure We Can canners, staff and supporters; the Pimp My Carroça team in São Paulo; The New School, especially the professors at Parsons School of Design; and CAPES for supporting this research.

\section{References}

GOWAN, T. American Untouchables: Homeless scavengers in San Francisco's underground economy. International Journal of Sociology and Social Policy 17 (3/4): 159-190, 1997. doi: 10.1108/eb013304.

GROW NYC. Recycling Facts. Accessed May 8, 2016. Available at http://www.grownyc.org/recycling/facts

HARLAND, R., SANTOS, M. C. L. Working with waste to dignify Human existence through collage as spontaneous design. In: Design, waste \& dignity. Coord. SANTOS, M. C. L. São Paulo, Ed. Olhares, 2014.

LYNCH, K. Wasting away. San Francisco, Sierra Club Books, 1990.

NAGLE, R. Picking up: on the streets and behind the trucks with the sanitation workers of New York City. New York City, Farrar, Straus and Giroux, 2013.

NYC MAYOR'S OFFICE OF SUSTAINABILITY. Waste and recycling. Accessed May 8, 2016.
Available at

http://www.nyc.gov/html/planyc/html/sustainability/wa ste-recycling.shtml

NYC DEPARTMENT OF SANITATION. New York City Curbside Waste Characterisation Study. New York City, 2013. Accessed May 8, 2016. Available at https://www1.nyc.gov/assets/dsny/docs/2013-WasteCharacterization-Study.pdf

\section{NYS DEPARTMENT OF ENVIRONMENTAL} CONSERVATION. New York's Bottle Bill. Accessed May 8, 2016. Available at http://www.dec.ny.gov/chemical/8500.html

DSNY. Stealing Recycling's Future. 2012. Accessed January 8, 2016. Available at https://www.youtube.com/watch?v=hAM-tW-uuIU

PEREIRA, M. C. G., TEIXEIRA, M. A. C. Struggle for recognition and public policies: An analysis of the experience of pickers belonging to Asmare in Belo Horizonte (state of Minas Gerais) 1987-2010. Design, Waste \& Dignity, coord. Maria Cecilia Loschiavo dos Santos. São Paulo, Ed. Olhares, 2014.

PIMPEX NY. Pimpex and Sure We Can: Visibility for NYC canners. 2016. Accessed January 8, 2017. Available at https://www.indiegogo.com/projects/pimpex-and-surewe-can-visibility-for-nyc-canners\#/

SMITH, N. Contours of a Spatialized Politics: Homeless Vehicles and the Production of Geographical Scale. Social Text (33): 54-81, 1992. doi: 10.2307/466434

SURE WE CAN. Sure We Can. Accessed April 21, 2016. Available at http:/www.surewecan.org/

TEODOSIO, A. S. S., DIAS, S. L. F. G. Recycling at the interstice of intersectorial relations: the national policy of solid wastes and challenges for the social, productive inclusion of pickers. In: Design, waste \& dignity. Coord. SANTOS, M. C. L. São Paulo, Ed. Olhares, 2014.

US ENVIRONMENTAL PROTECTION AGENCY. Advancing sustainable materials management: facts and figures 2013. New York City, 2015. Accessed May 8, 2016. Source:

https://www.epa.gov/sites/production/files/201509/documents/2013_advncng_smm_rpt.pdf

WILSON, D. C. Development drivers for waste management. Waste Manag Res. 25 (3): 198-207, 2007. doi: 10.1177/0734242X07079149. 